guidance, 21G,1.5inch needle was inserted in-plane approach. Right Costoclavicular block was given with $15 \mathrm{ml}$ of $0.75 \%$ Ropivacaine with $8 \mathrm{mg}$ Inj. Dexamethasone and subcutaneous infiltration of $10 \mathrm{ml}$ of $2 \%$ lignocaine with adrenaline for the blockade of intercostobrachial nerve and posterior cutaneous nerve of arm.

Results Costoclavicular block is also effective in the blockade of upper trunk of brachial plexus due to chimney effect. In the infraclavicular region, the neurovascular plexus sheath forms longitudinal septae between the cords that limits the circumferential spread of local anesthetics resulting in sparing of phrenic nerve. The success of anesthetic block is higher with multiple injections compared to single injection technique.

Conclusions Costoclavicular block is safer alternative for upper limb surgeries in case of polytrauma with compromised lung function.

\section{PLAN A BLOCKS COURSE}

T Al-Ani*, R Murphy. Glasgow Royal Infirmary, Glasgow, UK

\subsection{6/rapm-2021-ESRA. 168}

Background and Aims The consistency in education and training of regional anaesthesia could be achieved by focusing teaching on basic level yet high value nerve blocks. This quality improvement project aims to standardise regional anaesthesia teaching for anaesthetic trainees by delivering a 'Plan A' blocks course which covers: Interscalene brachial plexus (BP),

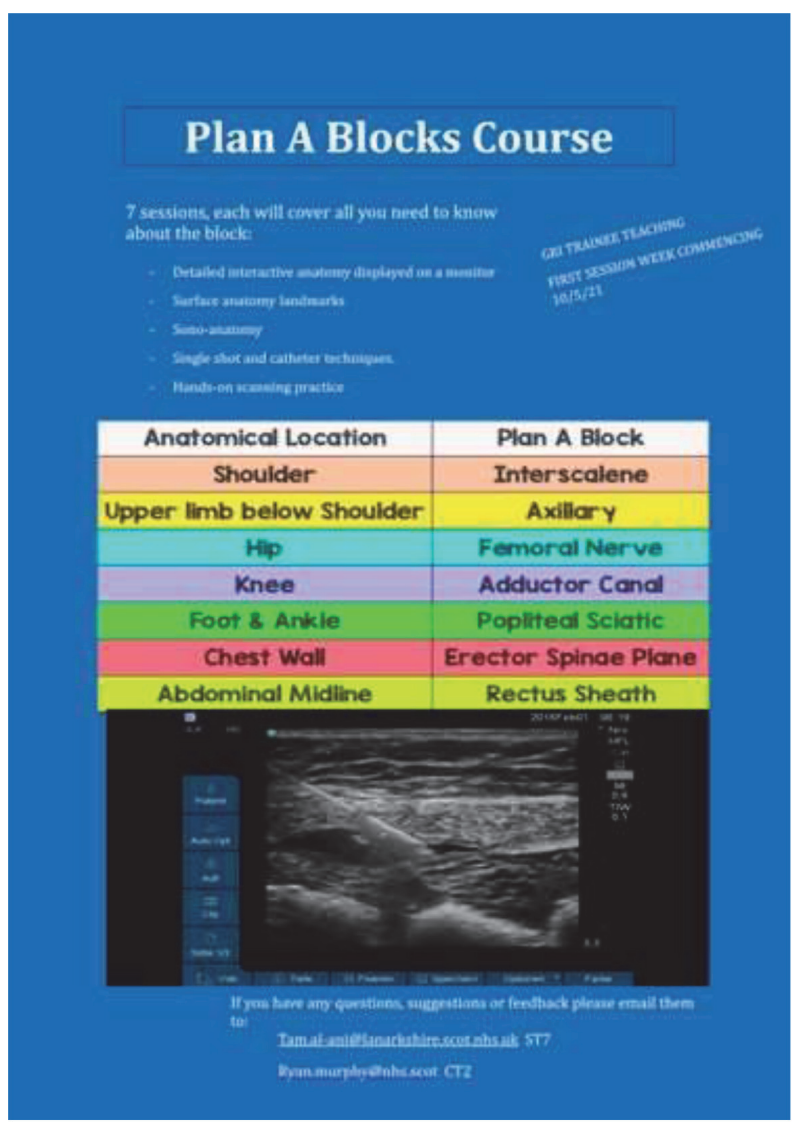

Abstract 168 Figure 1
Axillary BP, Femoral nerve, Adductor canal, Popliteal sciatic, Erector spine and Rectus sheath.

Methods The course is delivered across seven sessions and repeated four times a year. Each session is focused on one block at a time and lasts for one hour, covering: detailed anatomy, sono-anatomy, landmarks and ultrasound guided block techniques. Then, trainees get supervised hands on practice of landmarks and ultrasound scanning of a model. Ethics approval is not required as per NHS Greater Glasgow and Clyde policy.

Results The course is added to our formal anaesthetic department teaching. All attendees feedback has been positive, with all stating they would be more confident performing the 'Plan A' blocks after this course. This strongly supports the focused learning of one block at a time.

Conclusions Designing and delivering a 'Plan A' blocks course focusing on one core nerve block per session could improve the quality of regional anaesthesia learning.

\section{THE INFLUENCE OF COVID-19 PANDEMIC ON THE USE OF ULTRASOUND-GUIDED REGIONAL ANESTHESIA/ ANALGESIA TECHNIQUES FOR ORTHOPEDIC SURGERY CASES IN LESKOVAC GENERAL HOSPITAL, SERBIA}

${ }^{1} \mathrm{~N}$ Pejčić*, ${ }^{1} \mathrm{R}$ Mitić, ${ }^{1} \mathrm{M}$ Jović, ${ }^{2}$ Velickovic, ${ }^{3} \mathrm{~N}$ Sadana. 'Leskovac General Hospital, Leskovac, Serbia; ${ }^{2}$ SUNY Downstate, Brooklyn, USA; ${ }^{3}$ Tufts, Boston, USA

\subsection{6/rapm-2021-ESRA.169}

Background and Aims In Serbia, the use of regional anesthesia and analgesia (RA) techniques in orthopedic surgery cases has been low, despite sporadic efforts to increase the use. Thanks to the Kybele international teaching visit held in April 2017, members of the Department of Anesthesia at Leskovac General Hospital, Serbia (LGH) started doing ultrasound-guided RA (UGRA) techniques.

Methods From the LGH anesthesia database for period January 2016 to December 2020 data on all upper and lower extremity (LE) surgeries were obtained.

Results During the study period, there was an increase in neuraxial anesthesia (NA) use for LE surgery (2016 - 60\%, 2020

Abstract 169 Table 1

\begin{tabular}{|c|c|c|c|c|c|}
\hline \multicolumn{2}{|c|}{ Type of Surgery \Year } & 2017 & 2018 & 2019 & 2020 \\
\hline \multirow{4}{*}{ THA } & FIB & 1 & 1 & 0 & 0 \\
\cline { 2 - 6 } & QLB & 0 & 2 & 4 & 1 \\
\cline { 2 - 6 } & ESPB & 0 & 0 & 7 & 2 \\
\hline \multirow{4}{*}{ TKA } & ACB & 10 & 8 & 5 & 0 \\
\cline { 2 - 6 } & ACB + IPACK & 0 & 0 & 8 & 3 \\
\hline \multirow{4}{*}{ Lower Leg Surgery } & FNB & 2 & 0 & 0 & 0 \\
\cline { 2 - 6 } & SNB + FNB & 0 & 1 & 0 & 1 \\
\hline \multirow{5}{*}{ Arm Surgery } & Poppl.NB & 0 & 1 & 2 & 1 \\
\cline { 2 - 6 } & Poppl.NB+ACB & 7 & 8 & 5 & 4 \\
\hline & Interscalene NB & 1 & 1 & 0 & 1 \\
\cline { 2 - 6 } & Supraclavicular NB & 5 & 8 & 5 & 4 \\
\cline { 2 - 6 } & Axillar NB & 0 & 2 & 0 & 0 \\
\cline { 2 - 6 } & ESPB & 0 & 0 & 3 & 1 \\
\hline
\end{tabular}




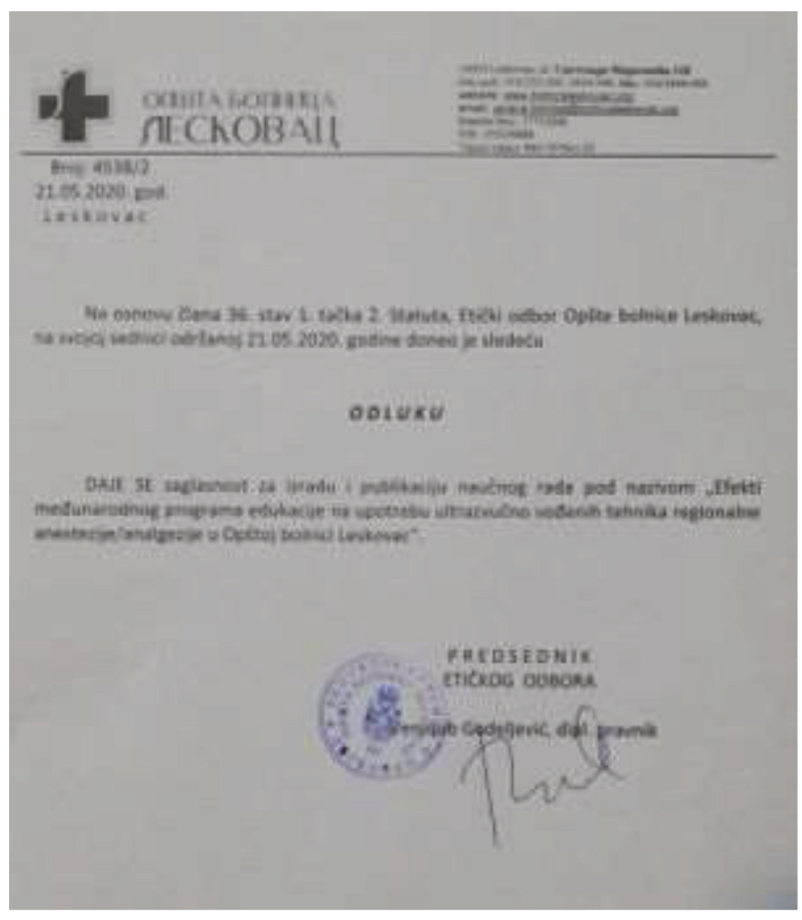

Abstract 169 Figure 1

\section{UGRA for Postoperative Pain Management}

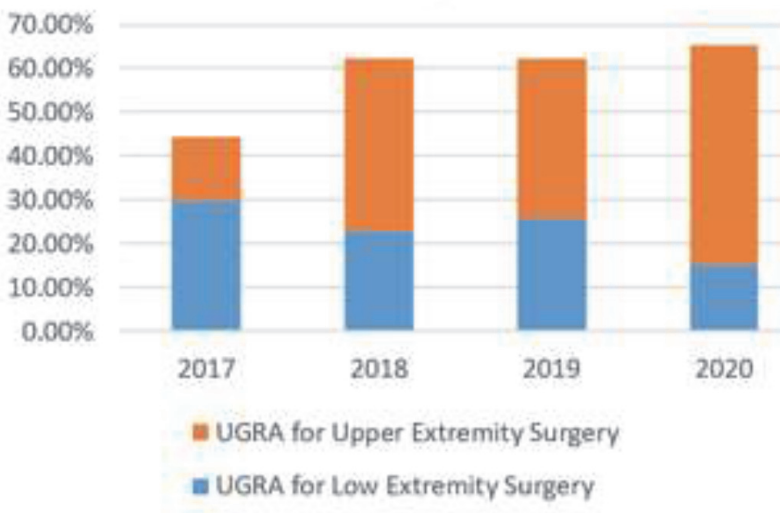

\section{Abstract 169 Figure 2}

- 78\%). There was also a small increase in both adductor canal (AC) and IPACK block use for postoperative pain management ${ }^{1}$, and sporadic use of quadratus lumborum (QL) and erector spinae plane (ESP) block following hip and femur surgery $^{2}$ (table 1). We had a significant increase in number of cases done under monitored anesthesia care and peripheral nerve block (supraclavicular brachial plexus block for arm surgery, and combination of popliteal and AC block for lower leg surgery) (table 1). In 2020, with decrease in trauma cases, the absolute number of UGRA blocks decreased, however the percentage of patients that received the block increased (table 1 , figure 1 ).

Conclusions It remains to be seen if current percentage of patients who have UGRA techniques will be maintained when the number of trauma cases returns to pre-COVID level.

\section{LUMPECTOMY UNDER INTERPECTORAL BLOCK AND PECTO-INTERCOSTAL FASCIAL BLOCK}

${ }^{1}$ D Morais*, ${ }^{2}$ C Lobo. ${ }^{1}$ CHTMAD, Vila Real, Portugal; ${ }^{2}$ Hospital das Forças Armadas - Pólo Porto, Porto, Portugal

\subsection{6/rapm-2021-ESRA.170}

Background and Aims Regional anestesia (RA) is a valuable alternative to general anesthesia (GA) in breast cancer surgery (BCS). In vitro studies suggest that RA might positively influence cancer outcome (1). We present a documented difficult airway case of a 80-year-old woman, proposed for lumpectomy under Interpectoral block (IPB) and Pecto-Intercostal Fascial Block (PIFB).

Methods A 80 year-old woman suffering from a non-controled severe obstructive sleep apnea, obesity (BMI 34) with a breast papilar carcinoma was proposed for lumpectomy $(23 \times 11 \mathrm{~mm}$ lesion at the internal quadrants).

Results She presented a IV Mallampati score (figure 1), thyromental distance $<6 \mathrm{~cm}$, class II upper-lip-bite test and

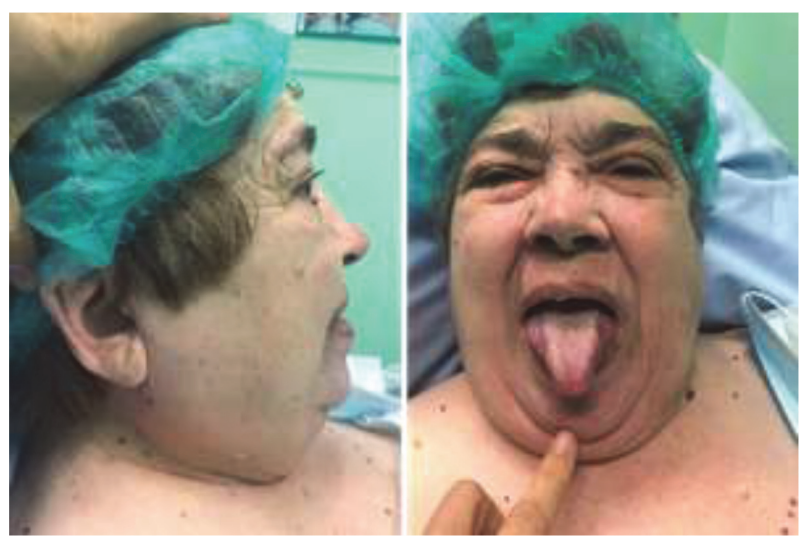

Abstract 170 Figure 1

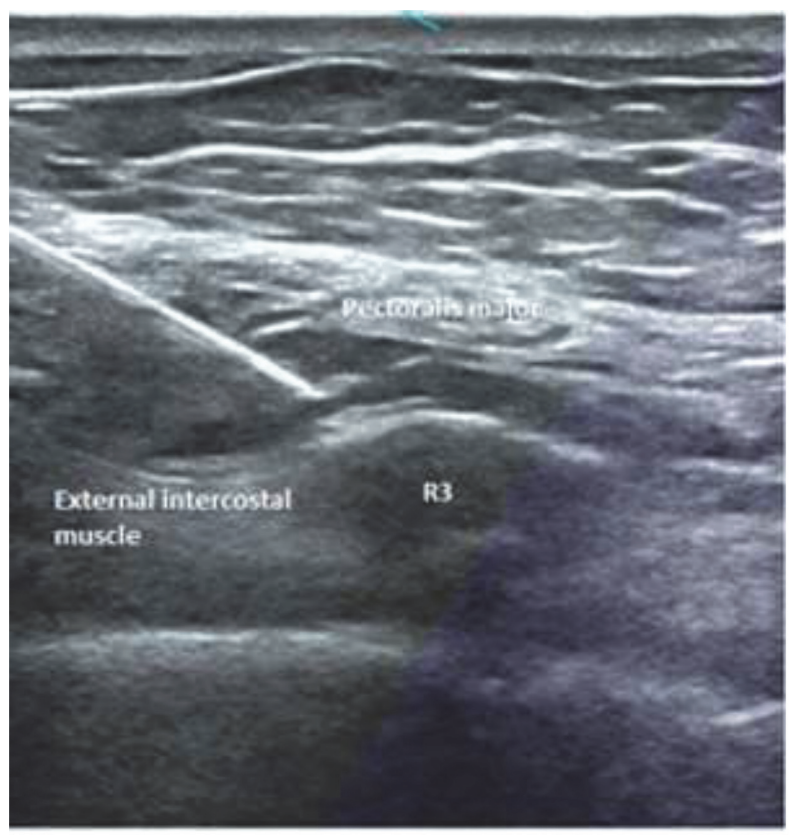

Abstract 170 Figure 2 